\title{
Construction and Practice of Information Demonstration Area in Mentougou District of Beijing
}

\author{
Juan Pan, Na Zhang*, Shan Yao, and Jian Xu \\ Department of Computer and Information Engineering, Beijing University of Agriculture, \\ Beijing, P.R. China 102206 \\ juan_pan@163.com
}

\begin{abstract}
The rural informatization is one of the important foundation for the construction of the metropolis-modern agriculture, which Beijing government makes great effort to develop now. Based on current situation of rural informatization construction in Mentougou district of Beijing, this study established an information demonstration area in order to integrate the information from the local natural ecology, agricultural production, special products trading and government. We made use of the technology of $3 \mathrm{~S}$, database and network to achieve the digitalization and visualization of the rural information. The study helps to guide the agricultural production and agricultural products circulation and offers the effective decision support for the sustainable development of the demonstration area.
\end{abstract}

Keywords: rural informatization, information demonstration area, 3S, information service platform, Eco-Agriculture.

\section{Introduction}

With the balance development of modern rural and urban areas, Beijing strengthens the rural informatization construction. The rural information infrastructure in Mentougou district has made remarkable progress after years of effort. An integrated basic information service network has been established, which provides a strong guarantee for Mentougou informatization construction (Shi 2009). 3S and Internet technology provide a new mode for the management of rural information, which realizes the management of spatial information that can't be carried out in the traditional one.

The Commission of Science and Technology of Mentougou district has established three websites successively-High-quality Goods Website, Chinese Walnut Website and Ecology Commercial City Website. However, the first two websites do not have the background system, and the third one needs to improve its trading function. Furthermore, these three websites provide some redundant function, and their network systems are instable. According to the current situation of informatization construction in Mentougou district, the study established information demonstration area in

${ }^{*}$ Corresponding author.

D. Li, Y. Liu, and Y. Chen (Eds.): CCTA 2010, Part I, IFIP AICT 344, pp. 367-373, 2011.

(C) IFIP International Federation for Information Processing 2011 
order to strengthen coordination and integration of rural information resources, and effectively promote the development of information technology in rural areas. We made use of $3 \mathrm{~S}$, database and network technology to manage and develop all kinds of rural information. Through the digitalization and visualization of the rural information, the study helps to guide the agricultural production and agricultural products circulation and offers the effective decision support for the sustainable development of the demonstration area.

\section{The Overview of Study Area}

Mentougou district is located in the southwest of Beijing, 62 kilometers east-west, 34 kilometers north-south, with a total area of 1,455 square kilometers. It is located at $115^{\circ} 25^{\prime} 00^{\prime \prime} \sim 116^{\circ} 10^{\prime} 07^{\prime \prime} \mathrm{E}, 39^{\circ} 48^{\prime} 34^{\prime \prime} \sim 40^{\circ} 10^{\prime} 37^{\prime \prime} \mathrm{N}$. The mountain area accounts for about $98.5 \%$ of the whole area, and the plain accounts for $1.5 \%$. The study area belongs to the middle latitude continental monsoon climate. It's droughty and windy in spring, hot and rainy in summer, cool and moist in fall, cold and dry in winter. There is great difference between western mountainous area and eastern plain in climate, the annual mean temperature is $11.7^{\circ} \mathrm{C}$ in the east and $10.2^{\circ} \mathrm{C}$ in the west. There are three rivers flowing through the study area- the Yongding River, Daqing River and Beiyun River. Yongding River covers the largest drainage area, which is about 1,368.03 square kilometers. Mentougou integrated ecosystem is composed of mountains, green fields and water system, which is an important ecological barrier and water source conservation area for Beijing. Therefore Mentougou is the key district to ensure the sustainable development of the Capital.

\section{Structure and Function of the System}

According to the requirement of the eco-conservation and terrain features, the study established the information demonstration area in order to improve the competitiveness of agricultural products, optimize and upgrade the rural economic structure, and transform the pattern of economic growth. The construction of information demonstration area made full use of the advantages of GIS in data management, information visualization and spatial information analysis, integrated the information of natural ecology, agricultural production, special products trading and government, and established an eco-agriculture information service platform. Two towns, Wangping and Miaofenshan, are firstly selected as the experimental units. Then the practice is extended to the whole district.

\subsection{Natural Ecological Information Module}

This module provides information display and query of meteorological, natural vegetation, hydrology, geology, soil type and so on. The meteorological information mainly involves temperature, relative humidity, precipitation and sunshine hours. 


\subsection{Agricultural Production Information Module}

This module mainly records the information of agricultural resources to realize the network management of agricultural production process. The information includes farm fields, soil nutrient, soil fertility, varieties of agricultural products, planting area, tree age and its spatial distribution. The soil nutrient includes the organic matter, total nitrogen, available nitrogen, available phosphorus, available potassium and $\mathrm{PH}$ value. In addition, according to standardized production practice, this module records the information of water and fertilizer management, training and pruning, pest control, growth process of crop and so on. All of the above mentioned information can be displayed and queried with the field parcel as a unit.

\subsection{Special Products Trading Module}

Mentougou district produces abundantly special products, such as pear, walnut, cherry, almond and apricot. Some products, named as the tributes to the imperial palace, are famous over China, especially the roses in Xiangjiangou Village, Miaofengshan town enjoy sound reputation both in domestic and overseas due to big flowers, thick petal, dense color, fragrant gout and high oil content. Special products trading module realizes online trading and product tracing. Online trading mainly includes product information publication and recommendation, agricultural product credit guarantees, payment function, distribution process and information flow records. For the function of tracing back the product information, the product identification codes are affixed to the smallest package. With the unique identification code, the platform can query the detailed records of production management, products processing, logistics distribution information, and builds the quality assurance system from the origin of product to the market.

\subsection{Government Affair Management Module}

This module issues the related policies and regulations information, and manages the daily business of towns and villages. The module emphasizes on the statistics analysis of social and economic data to provide the basic economic evaluation. The data includes numbers of households, total population, per capital annual net income, per capital disposable income, annual wages income, household business income, annual property income, annual transfer income, total expenditure and others.

\section{Implementing Scheme}

As shown in Fig.1, implementing scheme of the system is composed of data acquisition and processing, database construction and network platform construction. 


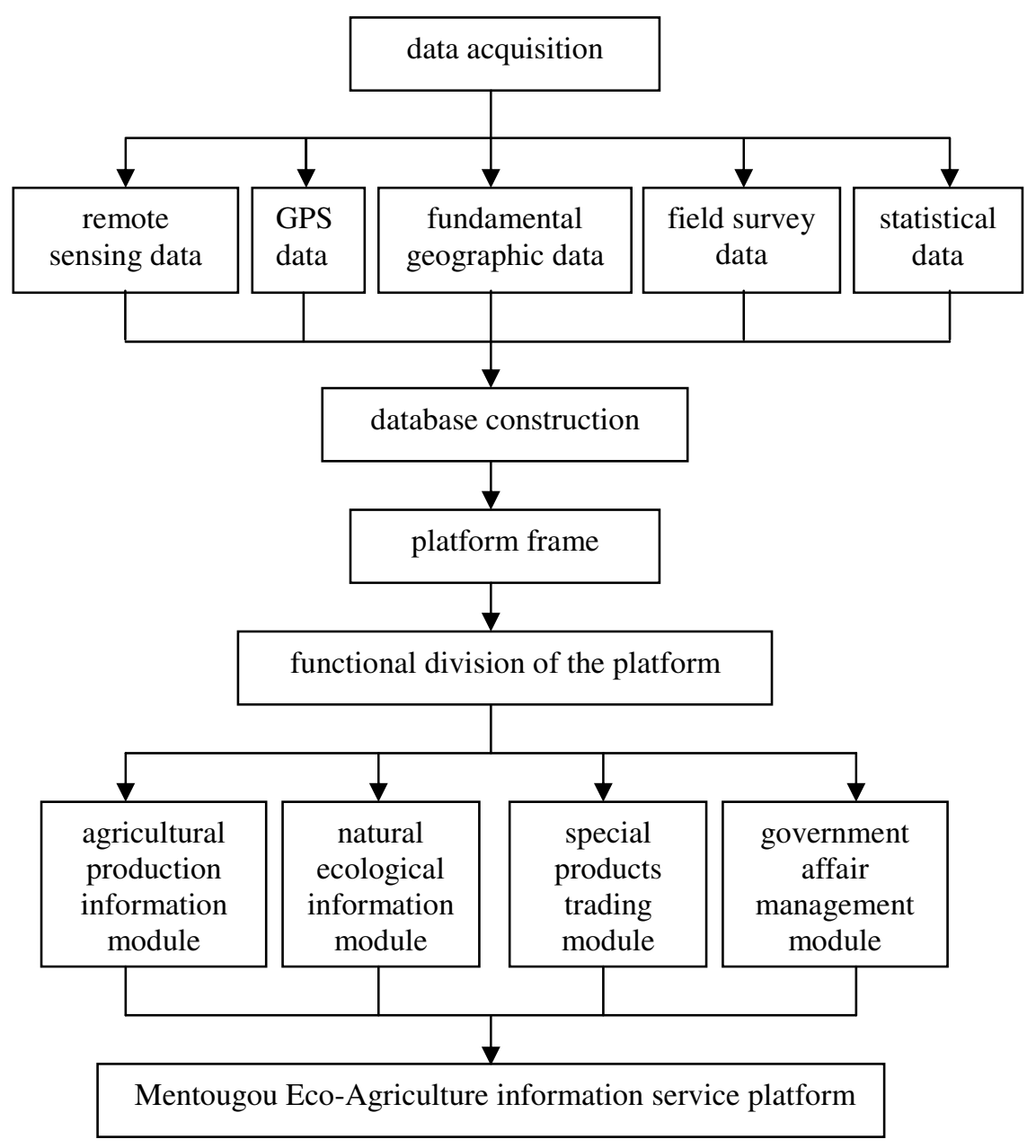

Fig. 1. Implementing scheme of the system

\subsection{Data Acquisition and Processing}

The basic data and maps need to be collected and integrated. The data includes satellite image map, basic map and thematic map, statistical data on rural economy over years, and other agricultural data of meteorology and envirnment and etc.

\subsection{Database Construction}

Rural information resources mainly include natural resource information, ecological information, agricultural production management information, agricultural market information and government affair information. All the information are processed, formatted and saved in the information resource database, which can be easily saved, retrieved, transmitted, published and shared through modern information technology. 
According to the local conditions, the information demonstration area constructs the spatial and attribute database, among which spatial information service is the basic database. The accuracy, capacity, coverage and update of spatial database not only affect the current construction of information demonstration area, but also have far-reaching influence on the economy of the district and the scientific value of the study. Spatial database integrates the information of topographic, traffic network, administrative division, soil type, soil nutrient, land use status, field parcel distribution, temperature, rainfall and so on. Attribute database includes agricultural production information, product trading information, product tracing and management of administrative villages. All the information is connected with field parcel data.

\subsection{Network Platform Construction}

The study establishes Mentougou Eco-Agriculture information service platform, using .NET, SQL Server and SuperMap as development tools, C\# as development language. The platform integrates four above-mentioned information management modules to realize the information query, analysis, decision-making, trading, trace back and others. The browser/server structure is applied to the system, and the client users can access the platform using a web browser.

\section{Function Actualization of System}

This paper takes management of space data and visualization showing for example to show the function actualization of system. Visualization showing interface of Mentougou geographical space data is showed as Fig.2, which realizes management and visualization of data such as village boundary, road, water system, soil, vegetation, landform, farmland and soil using style, etc. The system can brings plane map as well as three-dimensional relief map, both of the ways of showing can realize the zooming in and zooming out of the map. In addition, relief map has flight function, which

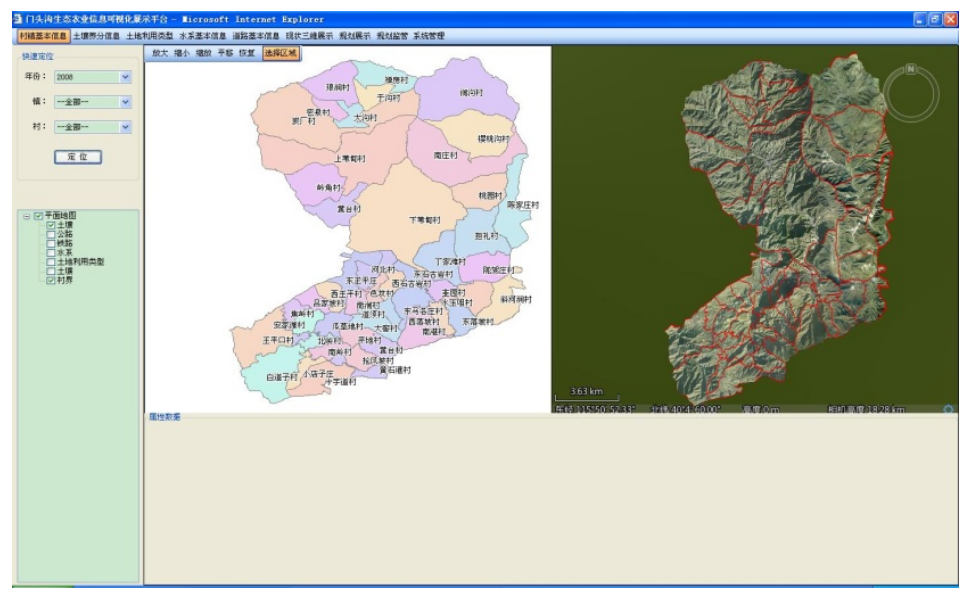

Fig. 2. Visualization showing interface of Mentougou geographical space data 
means the user can get access to related information of three-dimensional landform by user-defined route.

The system provides two query methods: query map by attribute and query attribute by map. As shown in Fig.3, based on the year, names of town and administrative village selected by the user, the system shows relevant positional information. When the user clicks on the map, the system will show information from the attribute database, such as area, numbers of households, agricultural population, income, climate, fertility of soil, etc.

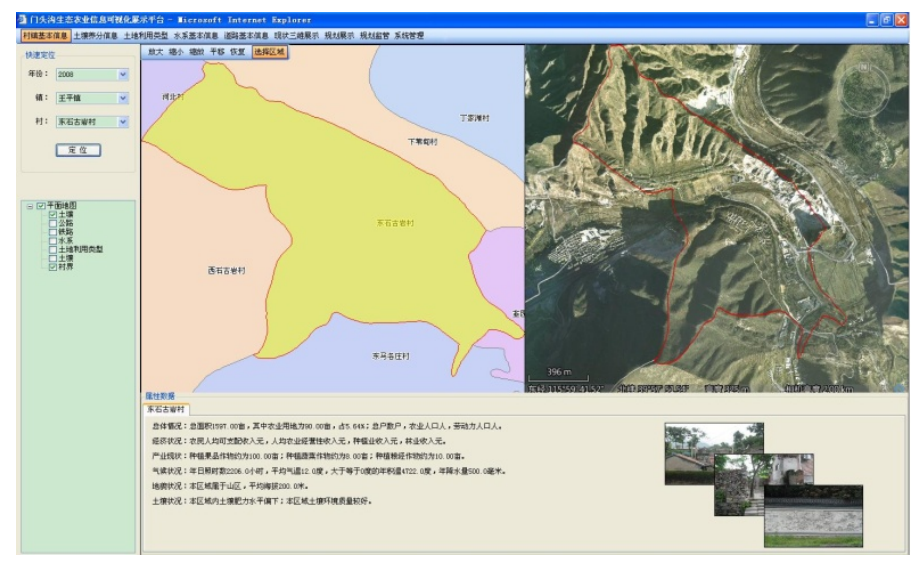

Fig. 3. Query result of administrative village

\section{Conclusion and Prospect}

The study establishes the information demonstration area based on the technology of .NET, $3 \mathrm{~S}$ and database to realize the integration of rural information resources. Through fully utilizing the advantages of GIS in map expression, spatial data management and map processing, the information service platform improves the visualization and convenient of management of rural information, advances the management efficiency of rural information.

Further study and discussion:

(1) To provide technical support for the planting structure adjustment, product variety update and agricultural division based on further study on the database of climate and agricultural resources.

(2) To establish the fertilizer recommendation system for green food according to the soil nutrient database of special products, and to provide scientific support for cultivation of high yield and quality with the study of the relation between soil nutrition status and product yield and quantity.

(3) To establish the remote sensing monitoring system to monitor diseases and insect pests of special products and provide real reference for decision-making.

(4) To build comprehensive evaluation model for ecological capacity maximizing the ecological, economic and social benefits in order to promote the virtuous circle of ecosystem, and provide decision support for sustainable development of the area. 


\section{Acknowledgments}

This study was funded by the Commission of Science and Technology of Mentougou district, and the project number is D0804090041000.

\section{References}

He, L.Y., Huang, W., Guo, Z.H., Miao, J.: Status, Task and Problem of Information Demonstration Village Construction in China. In: CCTA 2007, pp. 409-415 (2007) (in Chinese)

Li, M.: Demand Analysis and Development Strategy for Informatization of Rural Area in Beijing city. J. Agriculture Network Information, 47-49 (2009) (in Chinese)

Shi, Y.Q.: Reflections and Suggestions On Rural Informatization Construction in the Mountain Areas of Beijing. J. Agriculture Network Information, 41-44 (2009) (in Chinese)

Zhu, H.J., Wu, H.R., Feng, C., Zhong, X., Sun, X.: The Application of GIS in the Information Service Platform for New Village Construction. J. Journal of Agricultural Mechanization Research, 164-166 (2008) (in Chinese) 